\title{
Forecasting Economic, Social and Environmental Growth in the Sanitary and Service Sector Based on Thailand's Sustainable Development Policy
}

\author{
Pruethsan Sutthichaimethee ${ }^{1}$ \\ 1 Faculty of Economics, Chulalongkorn University, Wang Mai, Khet Pathum Wan, Bangkok, Thailand, e-mail: \\ pruethsan@gmail.com
}

\begin{abstract}
The purpose of this study is to forecast the long run implementation of Thailand's sustainable development policy in three main aspects, including economic, social and environmental aspect for the the sanitary and service sectors from 2016 until 2045. According to the national data for the years 2000-2015, based on the ARIMAX model, it has been found that Thai economy system is potentially changed and growing rapidly by $25.76 \%$, the population has grown by $7.15 \%$, and the Greenhouse gas emissions will gradually increase by $49.65 \%$, in the year 2045 . However, based on the analysis above, if Thailand fails to run the afore-mentioned policy properly, it will be difficult to successfully implement sustainable development, because the increased emission is moving in the same direction with economy and social aspect of Thailand.
\end{abstract}

Keywords: Sustainable development, population growth, GDP growth, Income per Capita, Greenhouse gas

\section{INTRODUCTION}

At present, the Thailand's economy has been continuously performing great, and has a potential to keep developing in the future. Having said that, the government has taken many initiatives to boost the economy and increase the per capita income for its people. In addition, Thailand tries to upgrade its status from a developing country, striving to become a developed one. According to the report of Asian Development Bank (ADB) (2007) and Thailand Development Research Institute (TDRI) (2007), the gross domestic product (GDP) of the country is growing steadily, especially there is in increase in both the domestic and foreign investment. In addition, Thailand also puts an effort to accelerate the investment growth better than in the past [Asian Development Bank: ADB 2014, Office of the National Economic and Social Development Board: NESDB 2015, Sutthichaimethee 2017]. Indeed, Thai government is concerned with its healthy growth in all areas. Thus, Thailand does whatever it takes to secure its overall welfare.
For instance, Thailand has waived taxes in some businesses. In addition, Thailand has helped her investors in the monetary form. Besides, based on the data of the year 2000 to 2015 , it shows that the population has continuously grown, and this basically accelerates its higher rate in consumption. Higher demand is especially noticeable in energy consumption. As a result, it brings continuous changes in economy [Sutthichaimethee and Danupon 2017]. Nevertheless, the government has been trying to preserve its environmental sustainability in establishing a sustainable development as quick as possible. In fact, both government and private agencies are in collaboration and continuous cooperation to attain its sustainable development. The Green project and the CSR Programs on Environmental Promotion and Conservation are the great examples of initiatives taken [Sutthichaimethee and Danupon 2017, Sutthichaimethee and Wanvicechanee 2015]. With all of these aspects put into consideration, this study is, conducted to predict how that policy is going to be in the future under the Thail government, and to see 
what can be done in order to develop the policy to achieve Thailand's objectives according to its national strategies [Thailand Development Research Institute: TDRI 2007].

\section{MODEL AND METHODOLOGY}

\section{ARIMAX model}

It is a model developed from the concept of ARIMA Model with the application of basic foundation in regression, and also, it attempts to eliminate the loopholes in the model that distort the economic, social, and environmental data of the country [Sutthichaimethee and Sawangdee 2016a, Thailand Development Research Institute: TDRI 2007]. The said model uses stationary data, and its analysis procedure is shown as below.

1. Use of the data to be analyzed for stationary by checking the unit root based on augment Dickey and Fuller concept.

Stationary stochastic process is the time series data associated with the mean or expected value, variance, co-variance and constant overtime. Time does not matter here; however, distance or lag does. $Y_{t}$ is denoted from the stochastic time series and it is stationary. Here, three properties must be presented as demonstrated below [Sutthichaimethee and Sawangdee 2016b, Xie et al 2015, Weijun et al 2015]:

$$
\begin{aligned}
& \text { Mean : } E Y_{t}=E Y_{t+k}=\mu \\
& \text { Variance : } \operatorname{VAR}\left(Y_{t}\right)=E\left(Y_{t-\mu}\right)^{2}=\sigma^{2} \\
& \text { Covariance : } E\left(Y_{t-\mu}\right)\left(Y_{t+k-\mu}\right)=\gamma_{k}
\end{aligned}
$$

From the equation (1), (2), and (3), it can be noticed that that $\gamma_{k}$ is covariance between $Y_{t}$ and $Y_{t+k}$. at the same time, there is the distance between two values of $Y$, but it will not fit with time. The best clarification to this occurrence is that random variables are stationary stochastic process. However, each time, the probability distribution remains the same. When $\varepsilon_{\mathrm{t}}$ lacks property, the expected value and constant varianceare white noise. This is to say that the autocorrelation property exists where the correlations are high or the order autoregressive process is bigger. Thus, a test like augmented Dickey Fuller (ADF) is needed. Moreover, the autocorrelation, heterosckas- ticity, and multicollinearity are to be eliminated [Sutthichaimethee and Danupon 2017, Zhao and Magoules 2012, Weijun et al 2015], and it can be done by adding higher lagged variables as shown below:

$$
\Delta Y_{t}=\delta_{1} Y_{t}+\sum_{i=2}^{p} \beta_{i} \Delta Y_{t-i+1}+\varepsilon_{t}
$$

$$
\begin{aligned}
\Delta Y_{t} & =\alpha_{1}+\delta Y_{t-1}+\sum_{i=2}^{p} \beta_{i} \Delta Y_{t-i+1}+\varepsilon_{t} \\
& \Delta Y_{t}=\alpha_{1}+\alpha_{2} T+\delta Y_{t-1}+ \\
& +\sum_{i=2}^{p} \beta_{i} \Delta Y_{t-i+1}+\varepsilon_{t}
\end{aligned}
$$

From the afore-mentioned equations, $p$ value is the lagged value of first difference to the variable, and this can be done by estimating the unit root and associating with the augmented Dickey Fuller method as stated below:

$$
\begin{aligned}
& \Delta Y_{t}=\alpha_{1}+\alpha_{2} T+\delta Y_{t-1}+ \\
& +\sum_{i=2}^{p} \beta_{i} \Delta Y_{t-i+1}+\varepsilon_{t}
\end{aligned}
$$

From this equation, three problems are considered, specifically the autocorrelation in $\varepsilon$ t is set to have white noise property in which the error term has 0 mean, and this lies constant with the hypotheses below:

$\mathrm{H} 0: \delta=0$, non-stationary

H1: $\delta<0$, non-stationary

If tau-statistics of the efficiency $\delta$ are in the absolute term form, more critical values are showing in the ADF table, and this rejects the major hypothesis, indicating that time series of variables are stationary. Hence, it is possible to say that $\Delta \mathrm{Y}_{\mathrm{t}}$ integrated number $\mathrm{d}$ represented by $\Delta \mathrm{Yt} \sim \mathrm{I}(\mathrm{d})$.

2. That same level stationary data from dependent variables and independent variables (at the level of $1^{\text {st }}$ moment and/or $2^{\text {nd }}$ moment only) are used to see the long-term relationship or co-integration in order to find out about the relevancy between each variable the long term and the same level. In addition, a vector error-correction model (ECM) must be shown and noticed here so as to establish the best model. 
The full information maximum likelihood (FIML) approach, as introduced by Johansen and Juselius (1990), is used in this study to retrieve the co-integrated relationships. This is due to the capacity of the model in accommodating two variables or more, and it does not require the specification of variables to test the number of cointegrating vector in which there are exogenous variable and endogenous variable.

3. To have the best model, the model is thus evaluated to ensure that independent variable is influential towards dependent variables. The tau-statistics values used to find the impacts in which $5 \%, 10 \%$, and $15 \%$ are the significance of difference.

4. Test this newly-built best model on these three kinds of problem. An autocorrelation is the first type.

4.1 Test the autocorrelation by using Lagrangian multiplier test - LM test

- LM test is applied when there are lagged variables of dependent variables appeared to be independent variables in the equation. In this test, it is not recommended to use Durbin-Watson. In addition, the LM is to find out more whether error terms have high level autocorrelation problem. The testing method is demonstrated below:

$$
\begin{aligned}
& Y_{t}=\alpha_{0}+\alpha_{1} X_{t}+\beta_{1} U_{t-1}+ \\
& +\beta_{2} U_{t-2}+\ldots+\beta_{p} U_{t-p}
\end{aligned}
$$

If $\mathrm{F}$ critical value is at the designated significant level, while $\chi^{2} \mathrm{p}$ and $\mathrm{F}_{\mathrm{m}, \mathrm{n}-\mathrm{k}}$ - test statistic is bigger than the value of Critical $\chi^{2}$, the major hypothesis is then rejected. In this context, at least one $\beta$ has the value differing from 0 , and this is to say that autocorrelation problem exists.

\subsection{Heteroskedasticity test by using ARCH test}

- ARCH testing is one of the methods to check heteroskedasticity in time series data. When the residual is retrieved, the lagged variables of the residual are computed with the residual by using the value of $\mathrm{F}$ and $\mathrm{nR}^{2}$ that has Chisquare distribution. Here, if heteroskedasticity is present, the hypothesis is then rejected. This can be clarified by seeing the critical value of $\chi^{2} \mathrm{p}$ from the table at the selected significant level which has a lower value than the $\chi^{2} \mathrm{p}$ statistical test.
4.3 Multicorrelinearity test by applying a correlation test and responses from correlogram value compared to chi-square value.

5. Assess the accuracy of the forecast to check the sample forecast capability. This assessment is done by computing the root mean square error (RMSE), the mean absolute (MAE), and the mean absolute percentage error (MAPE). In this study, the model chooses MAPE value of less than $30 \%$ in order to attain the best result with the least error [Sutthichaimethee 2017, Azdedh et al 2011, Lee and Tong 2012].

For this purpose ARIMAX model considers four main elements, namely auto regressive (AR), moving average (MA), exogenous variable and integrated (I) [Sutthichaimethee 2017, Dong et al 2015, Chienwattanasook and Sutthichaimethee 2012]. The model is shown as follows.

1. Auto regressive (AR) has the following characteristics:

$$
\begin{aligned}
& Y_{t}=\alpha+\beta_{1} Y_{t-1}+\beta_{2} Y_{t-2}+ \\
& +\ldots+\beta_{p} Y_{t-p}+\varepsilon_{t}
\end{aligned}
$$

where: $\beta_{1} \ldots \beta_{p}$ denotes parameters, $\alpha$ corresponds to a content, and $\varepsilon_{t}$ is the random variable (white noise).

2. Moving average (MA) uses the error term from the forecasting to see the differences between variables that actually happen (Y Actual) with the dependent variables (Y forecast) or $\varepsilon_{t}=Y_{a t}-Y_{f t}$ in the past to help in forecasting the variables required in the future. This can be seen below.

$$
\begin{aligned}
& Y_{t}=\delta+\varepsilon_{t}-\gamma_{1} \varepsilon_{t-1}- \\
& -\gamma_{2} \varepsilon_{t-2}-\ldots-\gamma_{q} \varepsilon_{t-q}
\end{aligned}
$$

where: moving average of order q or $\mathrm{MA}(\mathrm{q})$ by $\mathrm{q}$ means that the last order of error value is used.

3. Integrated (I) is to see the difference of variables. It is crucial to know the difference, because the ARIMA is non-stationary. With that, it is later possible to convert it to stationary model with the difference in $\mathrm{p}$ order.

The form of model development of ARIMA is ARIMA (p,d,q). That is order of $A R=p$ of $\mathrm{I}=\mathrm{d}$ and of $\mathrm{MA}=\mathrm{q}$. It cannot be denied that ARIMAX model is developed from ARIMA model, but this shall comply with the condi- 
tion of that a variety in designated dependent variable is to be energy consumption $(t)$ and independent variable, like energy consumption $(\mathrm{t}-\mathrm{i})$, population and GDP growth. In order to increase in the model capacity in terms of accuracy and forecasting in the future energy consumption, the researcher, therefore, chose to utilize the ARIMAX model [Sutthichaimethee 2017, Javanovic et al. 2015, Osorio et al. 2015].

\section{RESULTS AND DISCUSSION}

The results of the forecasting model of the greenhouse gas (GHG), population growth, and real GDP are classified by each category of the production. Unit Root Test with the adjust augmented Dickey-Fuller test is shown in Table 1.

\section{Result of the co-integration test}

The result in Table 1 bring all variables are stationary at the first difference to test co-integration by using the method of "Jansen Juselius" shown in Table 2.

As the results, "co-integration test" showed that model is a co-integration because of the trace test is 245.05 , which is higher than the critical value at significance level of $1 \%$ and $5 \%$, the maximum eigen value test at 221.05 which is higher than the critical value significance level of $1 \%$ and $5 \%$.

The result of ARIMAX model

ARIMAX model $1(2,1,2)$

$$
\begin{aligned}
& \Delta \ln (G H G)_{\mathrm{t}}=-0.22+4.05 \Delta \ln (G H G)^{* *}{ }_{\mathrm{t}-1}+ \\
& +3.17 \Delta \ln (G H G)^{* *}{ }_{\mathrm{t}-2}+4.69 \Delta \ln \\
& \text { Population } *{ }_{\mathrm{t}-1}+3.08 \Delta \ln (G D P)^{* *}{ }_{\mathrm{t}-1}+ \\
& +2.03 \mathrm{MA}^{*}{ }_{1}+2.05 \mathrm{MA}_{2}{ }_{2}+5.01 \mathrm{ECM}^{* *} \\
& \Delta \ln (\text { Population })_{\mathrm{t}} \quad=\quad-0.22+ \\
& +\quad 6.04 \Delta \ln \quad \text { (Population) }{ }^{*}{ }_{\mathrm{t}-1}+ \\
& +3.99 \Delta \ln (\text { Population }){ }_{\mathrm{t}-2}+4.01 \Delta \ln \\
& (G H G)^{* *}{ }_{t-1}+2.59 \Delta \ln (G D P)^{* *}{ }_{t-1}+ \\
& +2.57 M A^{* *}{ }_{1}+2.13 M A_{2}^{*}+3.14 E C M^{* *}
\end{aligned}
$$

$$
\begin{aligned}
& \Delta \ln (G D P)_{\mathrm{t}}=-0.11+3.97 \Delta \ln (\mathrm{GDP})^{* *}{ }_{\mathrm{t}-1}+ \\
& \quad+2.75 \Delta \ln (G D \mathrm{P})^{* *}+3.14 \stackrel{\Delta}{\mathrm{t}-2}+3 \ln \\
& \quad \text { Population } * *{ }^{\mathrm{t}-1}+4.64 \Delta \ln (G H G)^{* *}{ }_{\mathrm{t}-1}+ \\
& \quad+2.11 M A^{* *}+1.05 M{ }_{1}+{ }_{2}+3.02 E C M^{*}
\end{aligned}
$$

where: ${ }^{* *}$ is significance

$\alpha=0.01$,

$*$ is significance

$\alpha=0.05$,

$\mathrm{R}$-squared is 0.98 ,

Adjusted R-squared is 0.96 ,

Durbin-Watson stat is 2.21,

F-statistic is 279.05 (probability is 0.00 ), ARCH-test is 25.85 (probability is 0.10 ), $\mathrm{LM}$ - test is 1.77 (probability is 0.11 ) and response test $\left(\chi^{2}>\right.$ critical $)$ is significance.

The result obtained from the Sanitary and Service Sectors prediction from the year 2016 until 2045 with the use of ARIMAX model has shown that - in the upcoming year of 2045 the economy system in Thailand is gradually growing by up to $25.76 \%$, the population is potentially increasing approximately by $7.15 \%$, and greenhouse gas is potentially increasing by up to $49.65 \%$ (compared to the year of 2016). However, the ARIMAX model was tested for the effectiveness of the compared with the actual value. It was found that both models are highly effective with the low deviation and can be used for decision making shown in MAPE equal to $1.00,1.10$, and 1.75 , respectively, (less than $3 \%$ ) and test results showed that correlogram, the modeling value, can be used as the best model for predicting and forecasting the lowest tolerances value.

By reviewing the literature from many sources, the research has benefited a lot from them. For instance, Jain (2010) applies GrayMarkov model, Grey model with rolling mechanism, and singular spectrum analysis (SSA) to predict the consumption of conventional energy in India. On the other hand Weijun $\mathrm{Xu}$ et al. (2015) establish a new model with improved GM-ARIMA based on HP filter in order to forecast the final energy consumption of

Table 1. Unit root test at the first difference

\begin{tabular}{|c|c|c|c|c|c|c|}
\hline \multirow{2}{*}{ Variables } & \multirow{2}{*}{ Lag } & \multirow{2}{*}{ ADF Test } & \multicolumn{3}{|c|}{ MacKinnon Critical Value } & \multirow{2}{*}{ Status } \\
\cline { 4 - 7 } & & & $1 \%$ & $5 \%$ & $10 \%$ & \\
\hline $\operatorname{Ln}(G H G)$ & 1 & -4.63 & -4.22 & -3.36 & -3.25 & $\mathrm{I}(1)$ \\
\hline $\operatorname{Ln}($ Population $)$ & 1 & -5.13 & -4.22 & -3.36 & -3.25 & $\mathrm{I}(1)$ \\
\hline $\operatorname{Ln}(G D P)$ & 1 & -5.48 & -4.22 & -3.36 & -3.25 & $\mathrm{I}(1)$ \\
\hline
\end{tabular}


Table 2. Co-integration test by Johansen Juselius

\begin{tabular}{|c|c|c|c|c|c|c|c|c|}
\hline \multirow{2}{*}{ Variables } & \multirow{2}{*}{$\begin{array}{c}\text { Hypothesized } \\
\text { No. of } C E(S)\end{array}$} & \multirow{2}{*}{$\begin{array}{c}\text { Trace } \\
\text { Statistic Test }\end{array}$} & \multicolumn{2}{|c|}{$\begin{array}{l}\text { MacKinnon } \\
\text { Critical Value }\end{array}$} & \multirow{2}{*}{$\begin{array}{l}\text { Max-Eigen } \\
\text { Statistic Test }\end{array}$} & \multicolumn{2}{|c|}{$\begin{array}{l}\text { MacKinnon } \\
\text { Critical Value }\end{array}$} & \multirow[t]{2}{*}{ Status } \\
\hline & & & $1 \%$ & $5 \%$ & & $1 \%$ & $5 \%$ & \\
\hline \multirow{2}{*}{$\begin{array}{c}\Delta \mathrm{Ln}(G H G) \\
\Delta \operatorname{Ln}(\text { Population }) \\
\Delta \operatorname{Ln}(G D P)\end{array}$} & None $^{\star \star}$ & 245.05 & 19.75 & 15.41 & 221.05 & 15.68 & 14.07 & $\mathrm{I}(1)$ \\
\hline & At Most $1^{* *}$ & 75.11 & 5.75 & 3.16 & 71.35 & 5.75 & 3.16 & $\mathrm{I}(1)$ \\
\hline
\end{tabular}

Guangdong Province in China. Furthermore, Hsiai-Tien Pao et al. (2012) has employed the NGBM (nonlinear grey Bernoulli model) to anticipate carbon emissions, energy consumption and real outputs. The study has related to many previous studies, and found that there is no particular forecasting model could accurately perform and gives the lowest tolerances, whilst keeping closest to the actual data. One reason behind this phenomenon is that there is a lack of related variables to analyze or use statistical models that is seen to be the BLUE.

\section{CONCLUSION}

The study with the application of the ARIMAX model in the prediction has found that in between 2016 to 2045 - the above-mentioned rate greatly increases as well. These outcomes have pointed out that Thailand is well growing in economy, and the societies become more populated in a positive way. In contrast, there is a possibility that the environmental system will deteriorate, with the indication of an increment in greenhouse gas. Therefore, all necessary actions and movements must be initiated and taken by the government of Thailand to confirm that the environments, economy and societies are further improved and perform well. When these goals are achieved, the sustainable development can be implemented, while the possibility of destruction can be easily minimized.

\section{Acknowledgements}

This research is supported by Rachadapisek Sompote Fund for Postdoctoral Fellowship, Chulalongkorn University.

\section{REFERENCES}

1. Asian Development Bank (ADB). 2014. Environment, Climate Change, and Disaster Risk Management. Manila. Asian Development Bank.
2. Azadeh A., Asadzadeh S., Saberi M., Nadimi V., Tajvidi A., Sheikalishahi M. 2011. A neuro-fuzzystochastic frontier analysis approach for long-term natural gas consumption forecasting and behavior analysis: the cases of Bahrain, Saudi Arabia, Syria, and UAE. Appl Energy, 88, 3850-9.

3. Chienwattanasook Krisada, Sutthichaimethee Pruethsan. 2012. Trend of Thailand Jewelry Export to the USA Market. International Academy of Business and Economics, 12(3).

4. Dong B., Coa C., Lee S.E. 2015. Applying support vector machines to predict building energy consumption in tropical region. Energy Build, 37, 545-553.

5. Hao J., Liu D., Li Z., Chen Z., Kong L. 2012. Power system load forecasting based on fuzzy clustering and gray target theory. Energy Proc, 16, 1852-9.

6. Jovanovic RZ., Sretenovic' AA., Zivkovic' BD. 2015. Ensemble of various neural networks for prediction of heating energy consumption. Energy Build, 94, 189-99.

7. Lee Y-S., Tong L-I. 2012. Forecasting nonlinear time series of energy consumption using a hybrid dynamic model. Appl Energy, 94, 251-6.

8. Office of the National Economic and Social Development Board. 2015. National Income of Thailand. Bangkok: NESDB.

9. Osorio G., Matias J., Catalão J. 2015. Short-term wind power forecasting using adaptive neurofuzzy inference system combined with evolutionary particle swarm optimization, wavelet transform and mutual information. Renew Energy, 75, 301-307.

10. Sutthichaimethee P. 2017. VARIMAX Model to Forecast the emission of Carbon Dioxide from Energy Consumption in Rubber and Petroleum industries sectors in Thailand. Journal of Ecological Engineering, 18(3), 112-117.

11. Sutthichaimethee P., Tanoamchard W. 2015. Carrying Capacity Model of Food Manufacturing Sectors for Sustainable Development from using Environmental and Natural Resources of Thailand. Journal of Ecological Engineering, 16(5), 1-8.

12. Sutthichaimethee P., Ariyasajjakorn D. 2017. Forecasting Energy Consumption in Short-Term and Long-Term Period by using Arimax Model in the Construction and Materials Sector in Thailand. Journal of Ecological Engineering, 18(4), 52-59. 
13. Sutthichaimethee P., Sawangdee Y. 2016a. Model of Environmental Impact of Service Sectors to Promote Sustainable Development of Thailand. Ethics Sci Environ Polit, 16(1).

14. Sutthichaimethee P., Sawangdee Y. 2016b. Indicator of Environmental Problems Priority Arising from the use of Environmental and Natural Resources in Machinery Sectors of Thailand. Environmental and Climate Technologies, 17(1), 18-29.

15. Thailand Development Research Institute (TDRI). 2007. Prioritizing Environmental Problems with Environmental Costs. Final report prepared the Thailand Health Fund. Bangkok.
16. Xie N-M., Yuan C-Q., Yang Y-J. 2015. Forecasting China's energy demand and self sufficiency rate by grey forecasting model and Markov model. International Journal of Electrical Power and Energy Systems, 66, 1-8.

17. Weijun $\mathrm{Xu}$, Ren $\mathrm{Gu}$, Youzhu Liu, Yongwu Dai. 2015. Forecasting energy consumption using a new GM-ARMA model based on HP filter: The case of Guangdong Province of China. Economic Modelling, 45, 127-135.

18. Zhao H., Magoulès F. 2012. A review on the prediction of building energy consumption. Renewable Sustainable Energy Rev, 16, 3586-3592. 